\title{
Ensino de História, Didática de História,
} Educação Histórica:

alguns dados de pesquisa (2000-2005)

History Teaching, Didactic of History,
Historical Education:
some data of research (2000-2005)

\author{
Olinda Evangelista* \\ Jocemara Triches $^{* *}$
}

\begin{abstract}
RESUMO
O presente texto sistematiza informações, coligidas no site do Conselho Nacional de Desenvolvimento Científico e Tecnológico (CNPq), sobre grupos que pesquisam Ensino de História, Didática da História, Educação Histórica no Brasil, entre 2000 e 2005. Busca dar visibilidade a estes temas de investigação no âmbito das áreas de História e Educação. Constata a alta incidência do verbete Ensino de História; Didática da História apareceu timidamente em 2004 e Educação Histórica apenas em 2005. Verifica-se um crescimento exponencial no ano de 2004 de Grupos de Pesquisa (GP) de Ensino de História na área História e forte presença de GPs Ensino de História na área Educação. Os GPs, em sua maioria, estão sediados em instituições públicas de ensino superior e nas regiões Sul e Sudeste. A maior parte dos líderes é formada em História, tanto na graduação como na pós-graduação. Tal formação ocorreu majoritariamente na região Sudeste. Os líderes estão majoritariamente sediados em Centros de Educação ou de Ciências Humanas. A tendência acima se verifica também no que se refere às Linhas de Pesquisa nas duas áreas, constatando-se: crescimento no ano de 2004; maior presença na região Sudeste; concentração em instituições públicas. No que se refere aos dois outros verbetes - Didática da História e Educação Histórica - demonstra-se que GPs de DH apareceram em 2004 e de EH apenas em 2005. Sua presença é maior nas instituições públicas de ensino, na região sul e sudeste.

Palavras-chave: Ensino de História; Didática da História; Educação Histórica; Pesquisa e Grupos de pesquisa.
\end{abstract}

\begin{abstract}
The present text systematizes information collected from the website of the National Council of Scientific and Technological Development (CNPq), on groups that research History Teaching, Didacticism of History and Historical Education in Brazil, between the years 2000 and 2005. It intends to give visibility to these investigation themes in the ambit of the areas of History and Education. It verifies the high incidence
\end{abstract}


of the entry History Teaching; Didacticism of the History appeared timidly only in 2004 and Historical Education in 2005. An exponential growth is verified in the year of 2004 of Groups of Research of History Teaching in History area and also is verified strong presence of Groups of History Teaching in the Educational area. Groups, in its majority, is headquartered in public institutions of graduation education and in South and Southeast areas. Most of the leaders is formed in History, so much in the graduation as in to masters degree. Such formation happened for the most part in the Southeast area. The leaders are for the most part headquartered in Centers of Education or of Human Sciences. The tendency above is verified also in what refers to the Lines of Research in the two areas, being verified: growth in the year of 2004; larger presence in the Southeast area; concentration in public institutions. In what refers to the other two entries - Didacticism of the History and Historical Education - it is demonstrated that Groups of Didacticism of the History appeared in 2004 and of Historical Education just in 2005. Its presence is larger in the public institutions of teaching, in South and Southeast areas. Key-words: History Teaching; Didacticism of the History; Historical Education; Research and Groups of research.

\section{Introdução}

O presente texto tem uma intenção bastante delimitada: sistematizar algumas informações sobre grupos que pesquisam no Brasil, particularmente aquelas apresentadas pelo Conselho Nacional de Desenvolvimento Científico e Tecnológico $\mathrm{CNPq}^{1}$, entre 2000 e 2005. Tomando-as como base, foram organizados quadros que pudessem dar-lhes visibilidade como temas de investigação tanto na sua correlação com outras áreas de ensino, como na sua relação interna às áreas de História e Educação.

Na Busca Textual do Diretório de Grupos de Pesquisa do Brasil, do CNPq, foi possível coletar dados importantes e as ferramentas disponíveis permitem o seu cruzamento. Entretanto, muitos não puderam ser obtidos em razão do fato de que os pesquisadores não atualizaram as informações acerca de seus grupos de pesquisa ou de seus Currículos Lattes. Considerando essa restrição, foi possível traçar um mapa relativamente detalhado de Grupos de Pesquisa (GPs) e Linhas de Pesquisa (LPs) sobre Ensino de História, Didática da História, Educação Histórica, mas passível de ser questionado em sua abrangência e integralidade. Num primeiro momento, ao verificarmos o número total de GPs nas áreas de Educação e de História, constatamos a alta incidência do verbete Ensino de História; Didática da História apareceu timidamente em 2004 e Educação Histórica apenas em 2005. Em razão do assinalado, sistematizamos primeiramente as informações acerca de Ensino de História, averiguando com que freqüência a área de Ensino de aparecia em "todas as áreas" de investigação. O filtro foi depois especificado de modo a evidenciar como Ensino de História aparecia na grande área Ciências Humanas e nas áreas Educação e História. Essa busca foi realizada nos GPs e nas LPs, articuladas aos primeiros. Tal procedimento justifica-se, pois os GPs nem sempre trazem a palavra-chave Ensino de História em sua denominação. Desse modo, a busca foi realizada no diretório de GP, com base no nome do grupo, título da linha e palavras- chave do GP e da LP. Assim, um GP pode ter em sua denominação sem ter nenhuma linha com esse nome ou não conter em sua denominação Ensino de História, mas ter linhas dedicadas a ele. 
Um dos interesses desse levantamento foi apreender como as áreas História e Educação relacionam-se com Ensino de História - e depois com Didática da História e Educação Histórica - e quem são os responsáveis pelos GPs. Desse modo, após o levantamento inicial, procuramos informações acerca dos líderes tendo em vista conhecer sua formação na graduação e pós-graduação, sua base de atuação institucional e regional, bem como departamento e centro em que atuam. Como já referido, este texto é descritivo e tem como objetivo oferecer elementos a serem complementados com pesquisas que possibilitem um retrato mais fiel da área no que tange à investigação, bem como uma análise acurada.

\section{Os dados do CNPq}

O primeiro dado importante relaciona-se à presença das áreas Educação e História na distribuição dos GPs no Brasil. No Quadro 1 se constata que, no ano de 2000, a Educação ocupava a segunda posição em número de grupos de pesquisa - com 631 GPs, correspondente a 5,4\% do total de grupos cadastrados no diretório - e a História a $19^{\mathrm{a}}$ - com 200 GPs, correspondente a 1,7\%. Ao longo do período referido a Educação manteve a segunda posição - aumentando sua presença percentual para 5,9 (2002) e 6,1 (2004). A área de História registrou a $16^{a}$ posição em 2002, tendo caído para a $17^{\mathrm{a}}$ em 2004. Em termos percentuais, entretanto, subiu de 1,7 em 2002 para 1,9\% em 2004.

QUADRO 1 - DISTRIBUIÇÃO DOS GRUPOS DE PESQUISA POR ÁREA DO CONHECIMENTO PREDOMINANTE DO GRUPO - 2000-2004

\begin{tabular}{|c|c|c|c|c|c|}
\hline Área & Ano & GPs & Total GPs & $\mathbf{\%}$ & Posição \\
\hline Educação & 2000 & 631 & 11.760 & 5,4 & $2^{\mathbf{a}}$ \\
\hline História & 2000 & 200 & 11.760 & 1,7 & $19^{\mathrm{a}}$ \\
\hline & & & & & \\
\hline Educação & 2002 & 899 & 15.158 & 5,9 & $2^{\mathrm{a}}$ \\
\hline História & 2002 & 290 & 15.158 & 1,9 & $16^{\mathrm{a}}$ \\
\hline & & & & & \\
\hline Educação & 2004 & 1.194 & 19.470 & 6,1 & $2^{\mathrm{a}}$ \\
\hline História & 2004 & 364 & 19.470 & 1,9 & $17^{\mathrm{a}}$ \\
\hline
\end{tabular}

\subsection{Ensino de História: Grupos de Pesquisa}

A pesquisa por GPs Ensino de, em todas as áreas, indicou a existência de um crescimento desse campo de pesquisa: de 280 em 2000, para 942 em 2004. Especificando Ensino de História, todas as áreas e todas as palavras, obtivemos o resultado de 32 GPs em 2000 e 109 em 2004. Se tomarmos a mesma palavra-chave na área de Ciências Humanas, teremos a presença de 23 GPs em 2000 e 72 em 2004. Recortando a informação pela área Educação, chama a atenção que em 2000, Ensino de História contava com 20 GPs, subindo para 51 em 2004. Na área de História, tínhamos dois GPs em 2000, tendo subido para 11 em 2004. Nessas duas áreas relacionadas diretamente com Ensino de História verificou-se, pois, um crescimento dos GPs. Percentualmente esses números indicam um crescimento, entre 2000 e 2004, de 155\% na área de Educação e 450\% na de História. 
QUADRO 2 - GRUPOS DE PESQUISA, ENSINO DE E ENSINO DE HISTÓRIA, POR ÁREA - 20002004

\begin{tabular}{|c|c|c|c|}
\hline Filtro & $\mathbf{2 0 0 0}$ & $\mathbf{2 0 0 2}$ & $\mathbf{2 0 0 4}$ \\
\hline Ensino de, Todas as áreas & 280 & 650 & 942 \\
\hline Ensino de História, Todas as áreas & 32 & 61 & 109 \\
\hline Ensino de História, Ciências Humanas & 23 & 44 & 72 \\
\hline Ensino de História, Educação & 20 & 36 & 51 \\
\hline Ensino de História, História & 2 & 3 & 11 \\
\hline
\end{tabular}

Estabelecer a relação entre a presença de grupos de pesquisa na Educação e na História é necessário, pois os GPs de Ensino de História podem ser encontrados nas duas áreas, restando evidente que estão mais presentes na área da Educação. Essa presença, entretanto, precisa ser relativizada: na área Educação Ensino de História abrange a História de inúmeras áreas do conhecimento. O Quadro 3 expressa essa agregação. A História aparece com sete GPs, correspondendo a apenas 13\% do total. Outras áreas no campo educacional somam 50\% e a área de Ciências, genericamente tomada, aparece com 35\% do total dos GPs (18). Importante realçar que não se trata de GPs de áreas específicas das Ciências, mas da presença dessas áreas articuladas a Ensino de História desse conhecimento específico. Para efeito deste estudo, não consideramos Ensino de História da Física, por exemplo, como campo do Ensino de História como área de produção de conhecimento. De outro lado, ao se cotejar os GPs com as LPs constatamos que GPs que não trazem em sua denominação Ensino de História possuem LPs com esse nome. O Quadro 3, entretanto, não considerou esse elemento, concluindo que se verifica um crescimento entre 2000 e 2004 de três para sete GPs História.

QUADRO 3 - GRUPOS DE PESQUISA, ENSINO DE HISTÓRIA, ÁREA EDUCAÇÃO - 2000-2004

\begin{tabular}{|c|c|c|c|}
\hline Área & $\mathbf{2 0 0 0}$ & $\mathbf{2 0 0 2}$ & $\mathbf{2 0 0 4}$ \\
\hline História & 3 & 4 & 7 \\
\hline $\begin{array}{c}\text { História e Educação, Educação e Política Educacional, } \\
\begin{array}{c}\text { Formação Docente, Educação a Distância, Educação e } \\
\text { Sociedade, Educação e Cultura }\end{array}\end{array}$ & 9 & 16 & 21 \\
\hline Ciências Humanas, Filosofia & 0 & 2 & 1 \\
\hline Educação e Arte, Arte & 0 & 1 & 1 \\
\hline $\begin{array}{c}\text { Educação Científica, Educação e Ciências, Ciências, } \\
\text { Quimica, Fisica, Matemática, Ciências e Geografia }\end{array}$ & 8 & 11 & 18 \\
\hline Educação Física & 0 & 0 & 1 \\
\hline Linguagem, Lingua & 0 & 2 & 2 \\
\hline Total & 20 & 36 & 51 \\
\hline
\end{tabular}

FONTE: DISPONÍVEL EM: <HTTP://DGP.CNPQ.BR/BUSCAGRUPO/>

O Quadro 4 evidencia a incidência de GPs Ensino de História na área de História. Além dos GPs propriamente de História, aparecem outros dois, um ligado à Educação e outro à Ecologia. Verifica-se um crescimento exponencial no ano de 2004 de GPs Ensino de História na área História: de um para 10. 
QUADRO 4-GRUPOS DE PESQUISA, ENSINO DE HISTÓRIA, ÁREA HISTÓRIA - 2000-2004

\begin{tabular}{|c|c|c|c|}
\hline Área & $\mathbf{2 0 0 0}$ & $\mathbf{2 0 0 2}$ & $\mathbf{2 0 0 4}$ \\
\hline História & 1 & 3 & 10 \\
\hline História e Educação & 1 & 0 & 0 \\
\hline Ecologia e História & 0 & 0 & 1 \\
\hline
\end{tabular}

FONTE: DISPONÍVEL EM: <HTTP://DGP.CNPQ.BR/BUSCAGRUPO/>

Comparando os Quadros 3 (51 GPs) e 4 (11 GPs) percebemos que há uma forte presença de GPs Ensino de História na área Educação. Entretanto, ao pesquisarmos Grupo a Grupo e Linha a Linha, tomando apenas aqueles que apresentam essa especificidade, vamos encontrar nas duas áreas nove GPs.

No Quadro 5 podemos observar, então, os nove GPs Ensino de História, área Educação, destinados especificamente a esse estudo, independente das denominações dos GPs, e sua presença ao longo do período, bem como de seus líderes. O Quadro 5 evidencia o crescimento dos GPs, no período, de três para nove. No mesmo período, seis novos foram criados em 2004, três já existiam e dois foram descadastrados.

QUADRO 5 - GRUPOS DE PESQUISA, ENSINO DE HISTÓRIA, ÁREA EDUCAÇÃO, INSTITUIÇÕES, LÍDERES - 2000-2004

\begin{tabular}{|c|c|c|c|c|}
\hline Instituições $^{2}$ & Líderes & 2000 & 2002 & 2004 \\
\hline UFJF/MG & $\begin{array}{c}\text { Sonia Regina Miranda } \\
\text { Cassia Louro Palha }\end{array}$ & 1 & 0 & 0 \\
\hline $\begin{array}{c}\text { UNIJUÍ/ } \\
\text { FIDENE/RS }\end{array}$ & $\begin{array}{l}\text { Paulo Afonso Zarth }^{3} \\
\text { Helena Copetti Callai }\end{array}$ & 1 & 1 & 1 \\
\hline UFMG/MG & Lana Mara de Castro Siman ${ }^{4}$ & 0 & 1 & 1 \\
\hline UNICAMP/SP & $\begin{array}{c}\text { Ernesta Zamboni } \\
\text { Maria Carolina B. Galzerani }\end{array}$ & 1 & 0 & 0 \\
\hline USP/SP & Katia Maria Abud & 0 & 1 & 0 \\
\hline UFES/ES & Juçara Luzia Leite $^{5}$ & 0 & 1 & 1 \\
\hline $\mathrm{UFF} / \mathrm{RJ}$ & $\begin{array}{l}\text { Arlette Medeiros Gasparello }^{6} \\
\text { Heloisa de O. Santos Villela }\end{array}$ & 0 & 0 & 1 \\
\hline UFF/RJ & Sonia Maria Leite Nikitiuk $^{7}$ & 0 & 0 & 1 \\
\hline UERJ/RJ & Helena Amaral de Fontoura $^{8}$ & 0 & 0 & 1 \\
\hline UFSC/SC & $\begin{array}{l}\text { Maria de Fátima Sabino Dias }{ }^{9} \\
\text { Ivonete Silva Souza }\end{array}$ & 0 & 0 & 1 \\
\hline UFPB/PB & $\begin{array}{c}\text { Claudia Engle Cury } \\
\text { Antonio Carlos F. Pinheiro }\end{array}$ & 0 & 0 & 1 \\
\hline UFU/MG & $\begin{array}{l}\text { Selva Guimarães Fonseca } \\
\text { Regina Célia do Couto }\end{array}$ & 0 & 0 & 1 \\
\hline Total & & 3 & 4 & 9 \\
\hline
\end{tabular}

FONTE: DISPONÍVEL EM: <HTTP://DGP.CNPQ.BR/BUSCAGRUPO/>

O Quadro 6 evidencia as mesmas informações na área História. Observa- se que surgiram sete GPs e desapareceram dois ${ }^{12}$. A UEL é a instituição que manteve GP durante o período, sendo que em 2004 contava com dois GPs. 
QUADRO 6 - GRUPOS DE PESQUISA, ENSINO DE HISTÓRIA, ÁREA HISTÓRIA, INSTITUIÇÕES, LÍDERES - 2000-2004

\begin{tabular}{|c|c|c|c|c|}
\hline Instituição & Líderes & 2000 & 2002 & 2004 \\
\hline $\mathrm{UECE}^{13}$ & $\begin{array}{l}\text { Li: Francisco Adegildo Ferrer } \\
\text { Li: José Gerardo Vasconcelos }\end{array}$ & 1 & 0 & 0 \\
\hline UEL & $\begin{array}{c}\text { 2000- Li: André Luiz Joanilho } \\
\text { Li: Jozimar Paes de Almeida } \\
\text { 2002- Li: William Reis Meirelles } \\
\text { Li: Gilmar Arruda } \\
\text { 2004- Li: Marlene Rosa Cainelli }{ }^{14} \\
\text { Li: Gilmar Arruda } \\
\text { 2004- Li: Lúcia Helena de Oliveira Silva }{ }^{15} \\
\text { Li: Regina Célia Alegro }\end{array}$ & 1 & 1 & 2 \\
\hline UFPEL & Li: Sebastião Peres ${ }^{16}$ & 0 & 1 & 1 \\
\hline UNEB & $\begin{array}{l}\text { Li: Daniel Francisco dos Santos } \\
\text { Li: Wilson Roberto de Mattos }\end{array}$ & 0 & 1 & 0 \\
\hline UERJ & Li: Magali Gouveia Engel ${ }^{17}$ & 0 & 0 & 1 \\
\hline FURG & Li: Jussemar Weis Gonçalves ${ }^{18}$ & 0 & 0 & 1 \\
\hline UFCG & $\begin{array}{c}\text { Li: Fábio Gutemberg Ramos Bezerra de } \\
\text { Souza }^{19}\end{array}$ & 0 & 0 & 1 \\
\hline UFMT & $\begin{array}{l}\text { Li: Laci Maria Araújo Alves }{ }^{20} \\
\text { Li: Jocenaide Maria Rosseto Silva }\end{array}$ & 0 & 0 & 1 \\
\hline UFF & Li: Vânia Leite Fróes ${ }^{21}$ & 0 & 0 & 1 \\
\hline UNIFRA & Li: Marta Rosa Borin ${ }^{22}$ & 0 & 0 & 1 \\
\hline Total & & 2 & 3 & 9 \\
\hline
\end{tabular}

FONTE: DISPONÍVEL EM: <HTTP://DGP.CNPQ.BR/BUSCAGRUPO/> 0

Os dados dos Quadros 5 e 6 evidenciam o número de GPs, suas denominações, líderes e instituições. Considerando-se apenas o ano de 2004, dos nove GPs da área Educação, oito estão sediados em instituições públicas de ensino superior. Em termos regionais, seis localizam-se na Sudeste, dois na região Sul e um na Nordeste. Dos nove GPs da área Educação, sete localizam-se em instituições públicas. Doze são os líderes desses GPs, sendo que deles cinco se concentram na região Sul, dois na Sudeste, um na Nordeste e um na Centro-oeste. Conclui-se, então, que as regiões Sul e Sudeste concentram os GPs Ensino de História no Brasil.

O Quadro 7 evidencia a área de formação dos líderes dos GPs Ensino de História, área Educação, atuando no ano de 2004.

QUADRO 7 - GRUPOS DE PESQUISA, ENSINO DE HISTÓRIA, ÁREA DE EDUCAÇÃO, FORMAÇÃO ACADÊMICA DOS LÍDERES - 2000-2004 


\begin{tabular}{|l|l|l|}
\hline Graduação & Mestrado & Doutorado \\
\hline Geografia & História & História \\
\hline Geografia & Geografia & Geografia \\
\hline s/i & s/i & História \\
\hline História & História & História Social \\
\hline História & Educação & Educação \\
\hline s/i & s/i & Educação \\
\hline História & Educação & Educação \\
\hline Pedagogia & Educação & Saúde Pública \\
\hline História & História & Educação \\
\hline História & Educação & Não tem doutoramento \\
\hline História & Educação. & Educação \\
\hline História & Geografia & Educação \\
\hline História & História Social & História Social \\
\hline História & Educação & Não tem doutoramento \\
\hline
\end{tabular}

FONTE:

No que tange à Graduação, nove são formados em História, um em Pedagogia, um em Geografia e dois não informaram. A proeminência da área História na graduação diminui na pós-graduação: seis têm mestrado em Educação, quatro em História, dois em Geografia e dois não trazem informações; seis têm doutorado em Educação, quatro em História, um em Saúde Pública e dois não têm doutorado.

O Quadro 8, relativo à área História, indica, quanto à formação acadêmica dos líderes dos GPs Ensino de História, que no que toca à Graduação, os 12 são formados em História. Em nível de pós-graduação, seis são mestres em História, quatro em Educação, um em Sociologia e um não informou; oito são doutores em História e quatro em Educação. Apenas um tem pós-doutoramento.

QUADRO 8 - GRUPOS DE PESQUISA, ENSINO DE HISTÓRIA, ÁREA DE HISTÓRIA, FORMAÇÃO ACADÊMICA DOS LÍDERES - 2004

\begin{tabular}{|l|l|l|}
\hline Graduação & Mestrado & Doutorado \\
\hline Geografia & História & História \\
\hline Geografia & Geografia & Geografia \\
\hline s/i & s/i & História \\
\hline História & História & História Social \\
\hline História & Educação & Educação \\
\hline s/i & s/i & Educação \\
\hline História & Educação & Educação \\
\hline Pedagogia & Educação & Saúde Pública \\
\hline História & História & Educação \\
\hline História & Educação & Não tem doutoramento \\
\hline História & Educação. & Educação \\
\hline História & Geografia & Educação \\
\hline História & História Social & História Social \\
\hline História & Educação & Não tem doutoramento \\
\hline
\end{tabular}


O Quadro 9 traz informações de duas ordens: local de formação dos líderes e centros e departamentos de atuação. No que tange ao lugar de formação, nove obtiveram o Título de Mestre em instituições da região Sudeste, dois na região Sul, um na Nordeste. Dois não informaram. Em nível de Título de Doutor, 11 obtiveram seu título em instituições da região Sudeste, um no Canadá, dois não têm doutorado. A hegemonia da região Sudeste na formação dos pesquisadores em Ensino de História, na área Educação, é evidente.

No que se refere à local de atuação, dos 14 líderes, oito atuam em Centros ou Faculdades de Educação e seis não informaram. No caso de departamentos, três estão em departamentos ligados a Educação, dois a Estudos Sociais, um a Departamento de História e um a Colégio de Aplicação. Cinco não informaram. Chama a atenção o líder pertencente à Educação Básica, único caso nas duas áreas.

QUADRO 9 - GRUPOS DE PESQUISA, ENSINO DE HISTÓRIA, ÁREA DE EDUCAÇÃO, LOCAL DE ATUAÇÃO E FORMAÇÃO DOS LÍDERES - 2004

\begin{tabular}{|c|c|c|c|c|}
\hline Líderes & Centro & Departamento & Mestrado & Doutorado \\
\hline Paulo Afonso Zarth & $\mathrm{s} / \mathrm{i}$ & Estudos Sociais & UFF/RJ & UFF/RJ \\
\hline Helena C. Callai & $\mathrm{s} / \mathrm{i}$ & Estudos Sociais & USP/SP & USP/SP \\
\hline Lana M. de C. Siman & $\mathrm{s} / \mathrm{i}$ & $\mathrm{s} / \mathrm{i}$ & $\mathrm{s} / \mathrm{i}$ & Canadá \\
\hline Juçara Luzia Leite & $\begin{array}{c}\text { Centro } \\
\text { Pedagógico }\end{array}$ & Didática e Prática de Ensino & UFF/RJ & USP/SP \\
\hline Arlette M. Gasparello & $\begin{array}{l}\text { Faculdade de } \\
\text { Educação }\end{array}$ & Estudos Sociais Aplicados & UFF/RJ & $\mathrm{PUC} / \mathrm{SP}$ \\
\hline Heloisa de O. S. Villela & $\mathrm{s} / \mathrm{i}$ & $\mathrm{s} / \mathrm{i}$ & $\mathrm{s} / \mathrm{i}$ & USP/SP \\
\hline $\begin{array}{l}\text { Sonia M. Leite } \\
\text { Nikitiuk }\end{array}$ & $\begin{array}{l}\text { Faculdade de } \\
\text { Educação }\end{array}$ & $\begin{array}{c}\text { Educação, Sociedade, } \\
\text { Conhecimento }\end{array}$ & UFF/RJ & USP/SP \\
\hline Helena A. da Fontoura & $\mathrm{s} / \mathrm{i}$ & $\mathrm{s} / \mathrm{i}$ & UERJ/RJ & FIOCRUZ/RJ \\
\hline $\begin{array}{l}\text { Maria de Fátima S. } \\
\text { Dias }\end{array}$ & $\begin{array}{l}\text { Centro de } \\
\text { Ciências da } \\
\text { Educação }\end{array}$ & Metodologia de Ensino & UFSC/SC & UNICAMP/SP \\
\hline Ivonete Silva Souza & $\begin{array}{c}\text { Centro de } \\
\text { Ciências da } \\
\text { Educação }\end{array}$ & Colégio de Aplicação & UFSC/SC & Não tem Dr. \\
\hline Claudia Engler Cury & $\begin{array}{l}\text { Centro de } \\
\text { Educação }\end{array}$ & História & UNICAMP/SP & UNICAMP/SP \\
\hline Antonio C. F. Pinheiro & $\begin{array}{l}\text { Centro de } \\
\text { Educação }\end{array}$ & $\mathrm{s} / \mathrm{i}$ & UFPE/PE & UNICAMP/SP \\
\hline Selva G. Fonseca & $\begin{array}{l}\text { Faculdade de } \\
\text { Educação }\end{array}$ & $s / i$ & USP/SP & USP/SP \\
\hline Regina Célia do Couto & $\mathrm{s} / \mathrm{i}$ & $\mathrm{s} / \mathrm{i}$ & UFU/MG & Não tem Dr. \\
\hline
\end{tabular}

FONTE:

DISPONÍVEL

EM:

<HTTP://BUSCATEXTUAL.CNPQ.BR/BUSCATEXTUAL/BUSCAPESQ.JSP>

O Quadro 10 apresenta dados assemelhados ao anterior, relativos à área História. No que toca a lugar de formação, dos 12 líderes, quatro obtiveram o título de Mestre em instituições da região Sudeste, quatro na região Sul, dois na Centro-oeste, um na Nordeste, um não informou. Em nível de título de Doutor, sete obtiveram seu título em instituições da região Sudeste, três na Sul, um na Centro-oeste e um não tem o título. A hegemonia da região Sudeste na formação dos pesquisadores em Ensino de História se repete na área História. No que se refere ao local de atuação, dos 12 líderes, seis atuam em Centros de Ciências Humanas ou correlatos, um em Faculdade de Formação de 
Professores e um em Centro de Estudos Gerais e quatro não informaram. No caso de departamentos, 10 estão em departamentos de História e dois em Ciências Humanas.

QUADRO 10 - GRUPOS DE PESQUISA, ENSINO DE HISTÓRIA, ÁREA DE HISTÓRIA, LOCAL DE ATUAÇÃO E FORMAÇÃO DOS LÍDERES - 2004

\begin{tabular}{|l|l|c|c|c|}
\hline \multicolumn{1}{|c|}{ Líderes } & \multicolumn{1}{|c|}{ Centro } & Departamento & Msc. & Dr. \\
\hline Sebastião Peres & $\begin{array}{l}\text { Instituto de } \\
\text { Ciências } \\
\text { Humanas }\end{array}$ & História e Antropologia & PUC/RS & UFMG/MG \\
\hline Marlene Rosa Cainelli & $\begin{array}{l}\text { Letras e Ciências } \\
\text { Humanas }\end{array}$ & História & UFPR/PR & UFPR/PR \\
\hline Gilmar Arruda & $\begin{array}{l}\text { Letras e Ciências } \\
\text { Humanas }\end{array}$ & História & UNESP/SP & UNESP/SP \\
\hline $\begin{array}{l}\text { Lúcia Helena Oliveira } \\
\text { Silva }\end{array}$ & $\begin{array}{l}\text { Letras e Ciências } \\
\text { Humanas }\end{array}$ & História & UNICAMP/SP & UNICAMP/SP \\
\hline Regina Célia Alegro & $\begin{array}{l}\text { Letras e Ciências } \\
\text { Humanas }\end{array}$ & História & UEM/PR & UNESP/SP \\
\hline Magali Gouveia Engel & $\begin{array}{l}\text { Faculdade de } \\
\text { Formação de } \\
\text { Professores }\end{array}$ & Ciências Humanas & UFF/RJ & UNICAMP/SP \\
\hline $\begin{array}{l}\text { Jussemar Weiss } \\
\text { Gonçalves }\end{array}$ & \multicolumn{1}{|c|}{$\mathrm{s} / \mathrm{i} / \mathrm{s} / \mathrm{i}$} & História e Biblioteconomia & s/i & UFRGS/RS \\
\hline $\begin{array}{l}\text { Fábio Gutemberg Ramos } \\
\text { Bezerra de Souza }\end{array}$ & $\begin{array}{l}\text { Centro de } \\
\text { Humanidades }\end{array}$ & História e Geografia & UFPB/PB & UNICAMP/SP \\
\hline Laci Maria Araújo Alves & História & UFMS/MS & UNB/DF \\
\hline $\begin{array}{l}\text { Jocenaide Maria } \\
\text { Rosseto Silva }\end{array}$ & História & UFMT & $\begin{array}{c}\text { Não tem } \\
\text { doutorado }\end{array}$ \\
\hline Vânia Leite Fróes & $\begin{array}{l}\text { Centro de Estudos } \\
\text { Gerais }\end{array}$ & História & USP/SP \\
\hline Marta Rosa Borin & Humanas & PUC/RS & UNISINOS/RS \\
\hline
\end{tabular}

FONTE:

DISPONÍVEL

EM:

<HTTP://BUSCATEXTUAL.CNPQ.BR/BUSCATEXTUAL/BUSCAPESQ.JSP>

\subsection{Ensino de História: Linhas de Pesquisa}

Nas Linhas de Pesquisa procedeu-se o mesmo levantamento de dados, estando, alguns deles, mais explícitos em relação a Ensino de História. Conquanto algumas vezes a palavra-chave não apareça no nome do GP, ela aparece no das LPs. Verifica-se que na área Educação, em 2004, existiam 21 LPs e na área História nove. Tais dados, contudo, não são precisos, pois os mecanismos de busca do site do CNPq não permitem elencar todas as LPs vinculadas a Ensino de História. Por essa razão, foi necessário consultar cada GP das áreas Educação e História para verificar as LPs existentes de modo mais preciso. O Quadro que segue indica a presença majoritária de LPs na área Educação, entretanto esse número decresce quando mais bem examinadas as LPs; na área História, ao contrário, o número aumenta. Pelo Gráfico essa presença fica mais visível.

QUADRO 11 - LINHAS DE PESQUISA, ENSINO DE E ENSINO DE HISTÓRIA - 2000-2004 


\begin{tabular}{|c|c|c|c|}
\hline Filtro & $\mathbf{2 0 0 0}$ & $\mathbf{2 0 0 2}$ & $\mathbf{2 0 0 4}$ \\
\hline Ensino de, Todas as áreas & 180 & 403 & 630 \\
\hline Ensino de História, Todas as áreas & 14 & 26 & 43 \\
\hline Ensino de História, Ciências Humanas & 11 & 21 & 32 \\
\hline Ensino de História, Educação & 9 & 17 & 21 \\
\hline Ensino de História, História & 2 & 3 & 9 \\
\hline
\end{tabular}

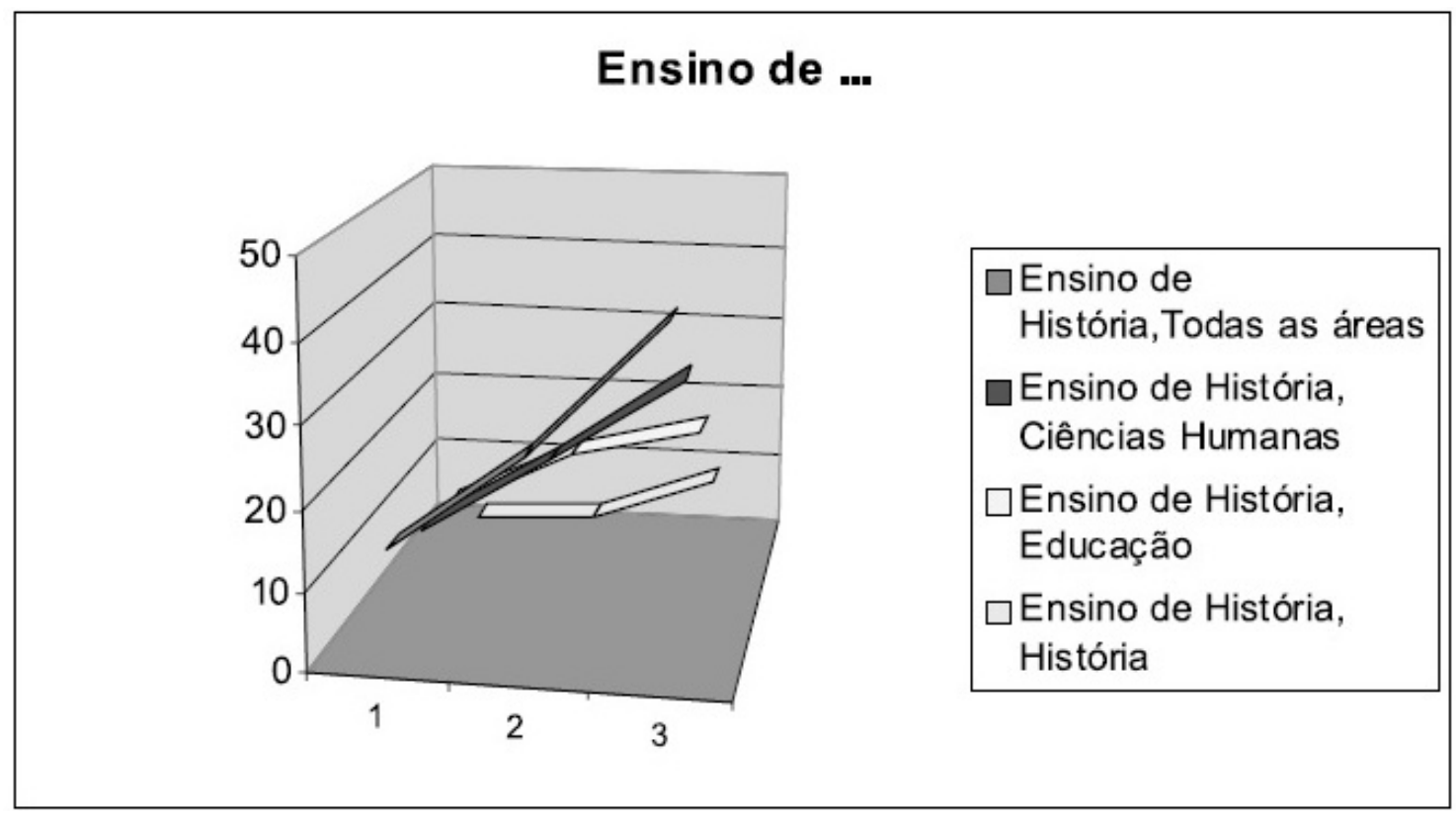

Embora a denominação Ensino de História apareça em menor escala com a formulação específica, ela aparecerá em maior escala quando associada a outras áreas do campo propriamente educativo e se configurará mais claramente em termos de LPs em seu interior. O Quadro que segue apresenta a configuração das LPs Ensino de História, todas as áreas, todas as palavras, assim como outras áreas agregadas. Pode-se verificar, então, que a participação de GPs sobre o tema na área História cresceu ao longo do período de 7 para 21 LPs. Isto é, quase a metade das LPs que referiram Ensino de História, de algum modo, nesse ano. A área de Ciências, de modo genérico, apresenta um importante número de LPs que discutem o Ensino de História, 14.

QUADRO 12 - LINHAS DE PESQUISA, ENSINO DE HISTÓRIA, TODAS AS ÁREAS - 2000-2004

\begin{tabular}{|c|c|c|c|}
\hline Áreas & $\mathbf{2 0 0 0}$ & $\mathbf{2 0 0 2}$ & $\mathbf{2 0 0 4}$ \\
\hline História & 7 & 12 & 21 \\
\hline Ciências, Matemática, Física & 6 & 9 & 14 \\
\hline Saúde & 1 & 2 & 6 \\
\hline Ciências Humanas, Filosofia & 0 & 2 & 1 \\
\hline Artes & 0 & 1 & 0 \\
\hline Português & 0 & 0 & 1 \\
\hline
\end{tabular}

FONTE: DISPONÍVEL EM: <HTTP://DGP.CNPQ.BR/BUSCAGRUPO/> 
Quando mais bem examinadas as LPs chegamos a outros números. O Quadro abaixo indica a presença de um número maior de LPs quando examinados mais detalhadamente os GPs. Desse modo, chegamos ao total de 12 LPs, articuladas a seis GPs. Nem todos os GPs que indicam Ensino de História em sua denominação ou em suas palavras-chave possuem LPs com essa referência. No caso da UFF/RJ temos dois GPs com quatro LPs.

QUADRO 13 - LINHAS DE PESQUISA, ENSINO DE HISTÓRIA, ÁREA EDUCAÇÃO, INSTITUIÇÕES - 2004

\begin{tabular}{|c|c|c|}
\hline Instituição $^{23}$ & Número & Linhas \\
\hline UNIJUÍ/FIDENE/RS & 1 & $\begin{array}{l}1 \text { - Metodologia do Ensino e História } \\
2 \text { - Ensino de História e novas tecnologias de } \\
\text { comunicação }\end{array}$ \\
\hline UFMG/MG & 1 & $\begin{array}{l}1 \text { - Ensino de História: cognição e cultura } \\
2 \text { - Ensino de História e educação patrimonial }\end{array}$ \\
\hline UFF/RJ & 2 & $\begin{array}{l}1 \text { - Ensino de História } \\
2 \text { - Ensino de História e de Ciências Sociais e } \\
\text { Epistemologia } \\
3 \text { - Ensino de História e de Ciências Sociais e } \\
\text { Tecnologias } \\
4 \text { - Ensino de História e de Ciências Sociais e } \\
\text { Fontes Documentais }\end{array}$ \\
\hline UERJ/RJ & 1 & Prática de Ensino em História \\
\hline UFPB/RJ & 1 & $\begin{array}{l}1 \text { - Linguagens contemporâneas e ensino de História } \\
2 \text { - Conhecimento Histórico: Ensino de História e } \\
\text { História da Educação } \\
3 \text { - História local: Pesquisa e ensino }\end{array}$ \\
\hline
\end{tabular}

FONTE: DISPONÍVEL EM: <HTTP://DGP.CNPQ.BR/BUSCAGRUPO/>

O Quadro abaixo demonstra a presença de 11 LPs Ensino de História, na área História, no ano de 2004, bem como as instituições que as sediam. Do ponto de vista regional, seis localizam-se na região Sul, três na Sudeste, uma no Mato Grosso e uma na Paraíba. A UEL/PR é a única instituição que, além de dois GPs, possui três LPs.

QUADRO 14 - LINHAS DE PESQUISA, ENSINO DE HISTÓRIA, ÁREA HISTÓRIA, INSTITUIÇÕES, NATUREZA JURÍDICA - 2004

\begin{tabular}{|c|c|c|}
\hline Instituição $^{24}$ & Número & Linhas \\
\hline UFPEL/RS & 1 & - Ensino de História \\
\hline UEL/PR & 2 & $\begin{array}{c}\text { - Cinema e História. O uso do filme como recurso didático } \\
\text { no ensino de História } \\
\text { - História e Ensino de História }\end{array}$ \\
\hline UERJ/RJ & 1 & $\begin{array}{c}\text { - Intelectuais, Historiografia e Ensino de História } \\
\text { - Saberes e Práticas no Ensino de História }\end{array}$ \\
\hline FURG/RS & 1 & - Ensino e História \\
\hline UFCC/PB & 1 & - Ensino de História \\
\hline UFMT/MT & 1 & - Memória, Cotidiano e Ensino de História \\
\hline
\end{tabular}




\begin{tabular}{|c|c|c|}
\hline UFF/RF & 1 & $\begin{array}{c}\text { - Produção Historiográfica e Ensino de História na Idade } \\
\text { Média }\end{array}$ \\
\hline UNIFRA/RS & 1 & - Educação e Ensino de História \\
\hline
\end{tabular}

FONTE: DISPONÍVEL EM: <HTTP://DGP.CNPQ.BR/BUSCAGRUPO/>

O Quadro seguinte evidencia o número de LPs Ensino de História na área Educação e na área História. Verifica-se que História, na área Educação, no ano de 2004, detém oito LPs, uma a menos que em 2002, mas quatro a mais que em 2000. Cabe à área geral de Ciências 10 LPs. No caso de Ensino de História, área História, o número de LPs, no ano de 2004, é de nove, expressando um crescimento importante no período: de duas em 2000 para nove em 2004. Se no âmbito dos GPs o número era o mesmo em ambas as áreas - nove -, o número de LPs na área Educação, oito, fica aquém do de História, nove.

QUADRO 15 - LINHAS DE PESQUISA, ENSINO DE HISTÓRIA, ÁREA EDUCAÇÃO, ÁREA HISTÓRIA - 2000-2004

\begin{tabular}{|c|c|c|c|}
\hline Área Educação & $\mathbf{2 0 0 0}$ & $\mathbf{2 0 0 2}$ & $\mathbf{2 0 0 4}$ \\
\hline História & 4 & 9 & 8 \\
\hline História e Ciências Sociais & 0 & 0 & 3 \\
\hline Ciências, Física, Matemática & 5 & 7 & 10 \\
\hline Artes Visuais & 0 & 1 & 0 \\
\hline Área História & $\mathbf{2 0 0 0}$ & $\mathbf{2 0 0 2}$ & $\mathbf{2 0 0 4}$ \\
\hline História & 2 & 3 & 9 \\
\hline
\end{tabular}

FONTE: DISPONÍVEL EM: <HTTP://DGP.CNPQ.BR/BUSCAGRUPO/>

Os Quadros que seguem demonstram a presença das LPs Ensino de História História e Educação - por região. Na área Educação, na região Sudeste encontram-se sete LPs, concentrando 58,3\%. A região Nordeste possui três (25\%) LPs e a Sul duas (16,6\%). As regiões Norte e Centrooeste não possuem LPs. Esses números podem estar incompletos em razão do fato de que nem sempre os GPs registram Linhas ou, mesmo, Linhas com o verbete Ensino de História. O Gráfico seguinte expressa esses totais.

QUADRO 16 - LINHAS DE PESQUISA, ENSINO DE HISTÓRIA, ÁREA EDUCAÇÃO, POR REGIÃO - 2004

\begin{tabular}{|c|c|c|}
\hline Região & Instituições & Número \\
\hline Norte & & 0 \\
\hline Nordeste & UFPB/PB & 3 \\
\hline Centro-Oeste & & 0 \\
\hline Sudeste & UFF/RJ, UERJ/RJ, UFMG/MG & 7 \\
\hline Sul & UNIJUÍ/FIDENE/RS & 2 \\
\hline Total & & 12 \\
\hline
\end{tabular}

FONTE: DISPONÍVEL EM: <HTTP://DGP.CNPQ.BR/BUSCAGRUPO/> 


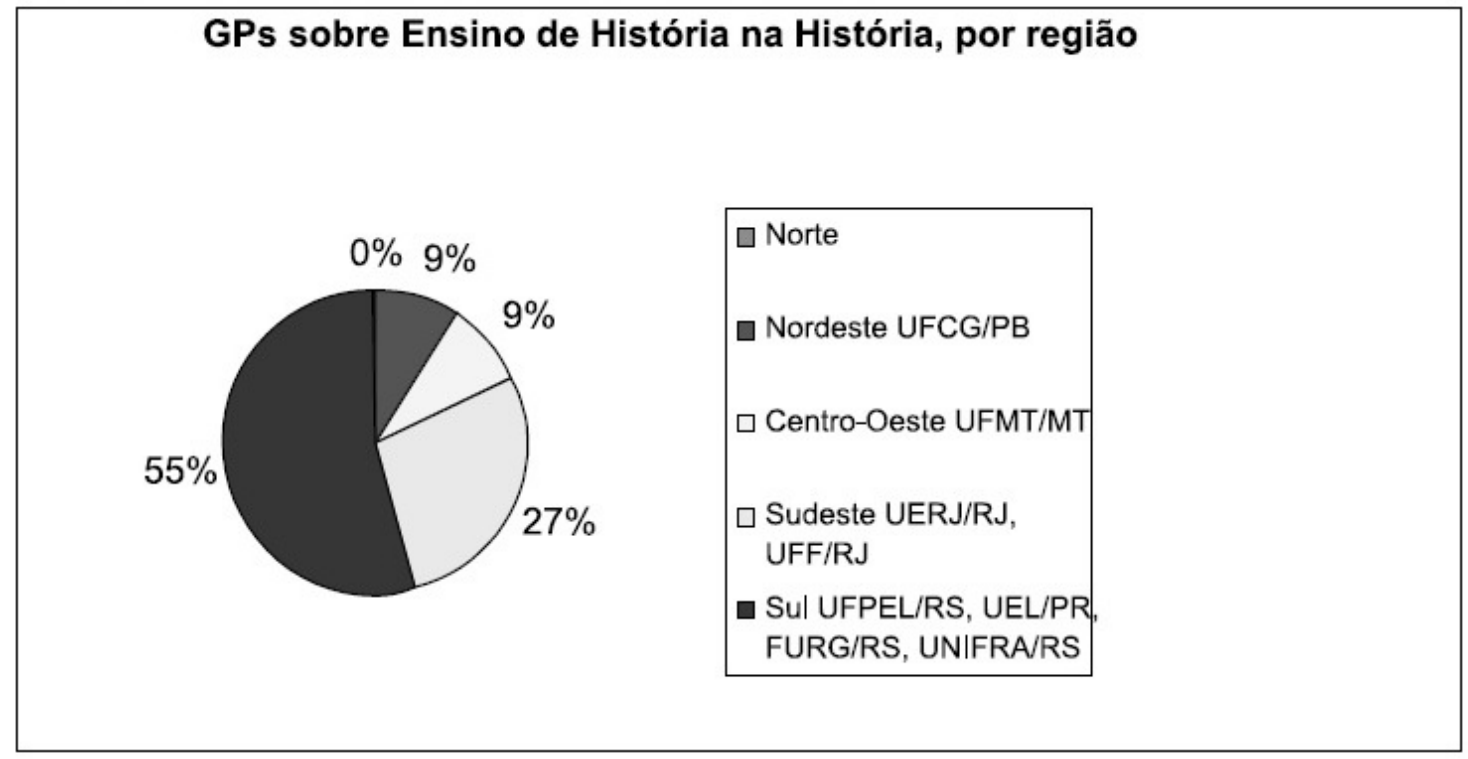

Na área História, a região Sul conta com seis LPs, isto é 54,5\%. A região Sudeste possui três LPs (27,2\%). As regiões Nordeste e Centrooeste possuem uma LP. A Norte não possui LP. Como no quadro anterior, esses números podem estar incompletos.

QUADRO 17 - LINHAS DE PESQUISA, ENSINO DE HISTÓRIA, ÁREA HISTÓRIA, POR REGIÃO $-2004$

\begin{tabular}{|c|c|c|}
\hline Região & Instituições & Número \\
\hline Norte & & 0 \\
\hline Nordeste & UFCG/PB & 1 \\
\hline Centro-Oeste & UFMT/MT & 1 \\
\hline Sudeste & UERJ/RJ, UFF/RJ & 3 \\
\hline Sul & UFPEL/RS, UEL/PR, FURG/RS, UNIFRA/RS & 6 \\
\hline Total & & 11 \\
\hline
\end{tabular}

GPS SOBRE ENSINO DE HISTÓRIA NA HISTÓRIA, POR REGIÃO 


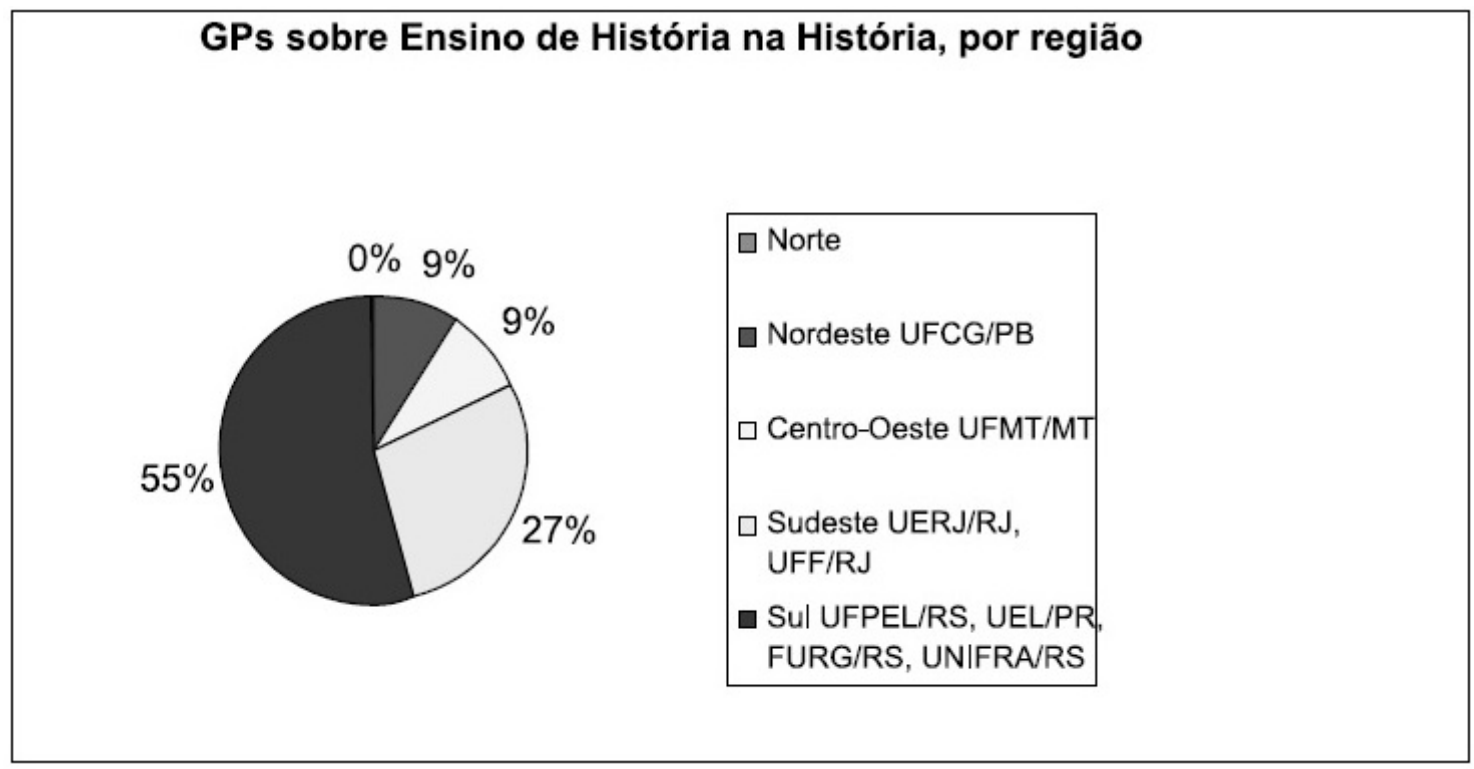

No próximo Quadro encontramos informações referentes à natureza jurídica das instituições. No caso da área História, as LPs concentram-se em instituições públicas de ensino, sete das nove IES. No caso da Educação, a maior parte também é pública, cinco das seis IES.

QUADRO 18 - LINHAS DE PESQUISA, ENSINO DE HISTÓRIA, ÁREAS HISTÓRIA E EDUCAÇÃO, INSTITUIÇÕES, NATUREZA JURÍDICA - 2004

\begin{tabular}{|c|c|c|c|}
\hline $\begin{array}{c}\text { Instituição }^{25} \\
\text { Histórica }\end{array}$ & Natureza & $\begin{array}{c}\text { Instituição } \\
\text { Educação }\end{array}$ & Natureza \\
\hline UFPEL/RS & Pública & FIDENE/RS & Privada \\
\hline UEL/PR & Pública & UFMG/MG & Pública \\
\hline UEL/PR & Pública & UFF/RJ & Pública \\
\hline UERJ/RJ & Pública & UERJ/RJ & Pública \\
\hline FURG/RS & Privada & UFPB/PB & Pública \\
\hline UFCG/PB & Pública & & \\
\hline UFMT/MT & Pública & & \\
\hline UFF/RJ & Pública & & \\
\hline UNIFRA/RS & Pública & & \\
\hline
\end{tabular}

FONTE: DISPONÍVEL EM: <HTTP://DGP.CNPQ.BR/BUSCAGRUPO/>

\section{Didática da História e Educação Histórica : Grupos e Linhas de Pesquisa}

Como restou claro, o presente estudo procurou colher informações no site do CNPq acerca da pesquisa, no país, em Ensino de História, Didática da História e Educação Histórica. O predomínio entre 2000 e 2004 foi de Ensino de História, período em que o censo sobre os pesquisadores e as pesquisas está mais bem organizado. Entretanto, pesquisadores da área vêm registrando os verbetes Didática da História e Educação Histórica, tendência mais recente.

Em termos de GP, na área Educação, Didática da História aparece em 2004 com um grupo apenas, localizado na UEPG. Na área de História, o mesmo fenômeno ocorre, surgindo um GP na UFBA. Ambas são instituições públicas e os líderes têm formação tanto na área de Educação quanto na de História. Isto é, todos são graduados em 
História, dois têm mestrado em Educação e um tem doutorado em Educação. Os outros dois têm doutorado em Sociologia e Cinema e Audiovisual.

QUADRO 19 - GRUPOS DE PESQUISA, DIDÁTICA DA HISTÓRIA, ÁREAS HISTÓRIA E EDUCAÇÃO, LÍDERES, INSTITUIÇÃO, FORMAÇÃO - 2000-2004

\begin{tabular}{|l|l|l|l|l|}
\hline \multicolumn{1}{|c|}{ Instituição } & \multicolumn{1}{c|}{ Área } & \multicolumn{1}{c|}{$\mathbf{2 0 0 4}$} & \multicolumn{1}{c|}{ Líder } & \multicolumn{1}{c|}{ Formação } \\
\hline $\begin{array}{l}\text { Universidade } \\
\text { Estadual de Ponta } \\
\text { Grossa- UEPG }\end{array}$ & Educação & $\begin{array}{l}\text { Grupo de Estudos } \\
\text { em Didática da } \\
\text { História. }\end{array}$ & $\begin{array}{l}\text { Luis Fernando } \\
\text { Cerri }\end{array}$ & $\begin{array}{l}\text { Gr: História } \\
\text { Msc: Educação } \\
\text { Dr: Educação }\end{array}$ \\
\hline $\begin{array}{l}\text { Universidade } \\
\text { Federal da Bahia } \\
\text { UFBA }\end{array}$ & História & $\begin{array}{l}\text { Oficina Cinema- } \\
\text { História }\end{array}$ & $\begin{array}{l}\text { Jorge Luiz B. } \\
\text { Nóvoa }\end{array}$ & $\begin{array}{l}\text { Gr: História } \\
\text { Msc: Ciências Sociais } \\
\text { Dr: Sociologia }\end{array}$ \\
& & $\begin{array}{l}\text { Cristiane } \\
\text { Carvalho da } \\
\text { Nova }\end{array}$ & $\begin{array}{l}\text { Msc: Educação } \\
\text { Dr: Cinema e Audiovisual }\end{array}$ \\
\hline
\end{tabular}

FONTE: DISPONÍVEL EM: <HTTP://DGP.CNPQ.BR/BUSCAGRUPO/>

No caso das LPs, duas foram localizadas na UEPG, em 2004, na área Educação e nenhuma na área História.

QUADRO 20 - LINHAS DE PESQUISA, DIDÁTICA DA HISTÓRIA, ÁREAS HISTÓRIA E EDUCAÇÃO, INSTITUIÇÃO - 2000-2004

\begin{tabular}{|l|l|l|}
\hline Instituição & Área & $\mathbf{2 0 0 4}$ \\
\hline UEPG & Educação & Didática da História no Brasil - Séc. XX \\
\hline UEPG & Educação & Formação de Professores de História \\
\hline----- & História & --------- \\
\hline
\end{tabular}

FONTE: DISPONÍVEL EM: <HTTP://DGP.CNPQ.BR/BUSCAGRUPO/>

Ao pesquisarmos o verbete Educação Histórica encontramos um GP na UFMG, na área Educação, registrado desde 2002. Na área História, encontramos um GP na UFBA, que corresponde ao mesmo encontrado no verbete Didática da História. No que tange às LPs, na área Educação nenhuma foi registrada. Na área História encontramos uma LP na UFPB, no ano de 2004. Tais dados podem ser vistos nos quadros que seguem. De novo os GPs se encontram em instituições públicas e dois dos líderes são graduados em História (os dois já referidos nos GPs, um em Ensino de História e outro em Didática da História), variando os mestrados e doutorados: um tem mestrado em Educação e um em Ciências Sociais; um tem doutorado em Cinema e Audiovisual, um em Sociologia e um em Didática da História.

QUADRO 21 - GRUPOS DE PESQUISA, EDUCAÇÃO HISTÓRICA, ÁREAS EDUCAÇÃO E HISTÓRIA, INSTITUIÇÃO, LÍDER, FORMAÇÃO - 2000-2004 


\begin{tabular}{|c|c|c|c|c|c|}
\hline Instituição & Área & 2004 & 2002 & Líder & Formação \\
\hline UFMG & Educação & $\begin{array}{l}\text { Ensino de } \\
\text { História: } \\
\text { cognição e } \\
\text { cultura }\end{array}$ & $\begin{array}{l}\text { Ensino de } \\
\text { História: } \\
\text { cognição e } \\
\text { cultura }\end{array}$ & $\begin{array}{l}\text { Lana Mara de Castro } \\
\text { Siman }\end{array}$ & $\begin{array}{l}\text { Dr: Didática da } \\
\text { História }\end{array}$ \\
\hline UFBA & História & $\begin{array}{l}\text { Oficina } \\
\text { Cinema- } \\
\text { História }\end{array}$ & ----- & $\begin{array}{l}\text { Jorge Luiz Bezerra } \\
\text { Nóvoa } \\
\text { Cristiane Carvalho da } \\
\text { Nova }\end{array}$ & $\begin{array}{l}\text { Gr: História } \\
\text { Msc: Ciências Sociais } \\
\text { Dr: Sociologia } \\
\text { Gr: História } \\
\text { Msc: Educação } \\
\text { Dr: Cinema e } \\
\text { Audiovisual }\end{array}$ \\
\hline
\end{tabular}

FONTE: DISPONÍVEL EM: <HTTP://DGP.CNPQ.BR/BUSCAGRUPO/>

QUADRO 22 - LINHAS DE PESQUISA, EDUCAÇÃO HISTÓRICA, ÁREAS DE EDUCAÇÃO E HISTÓRIA, INSTITUIÇÃO - 2000-2004

\begin{tabular}{|l|l|l|}
\hline Instituição & Área & $\mathbf{2 0 0 4}$ \\
\hline UFPB & Educação & Estudos Culturais e Educação Histórica \\
\hline- & História & - \\
\hline
\end{tabular}

FONTE: DISPONÍVEL EM: <HTTP://DGP.CNPQ.BR/BUSCAGRUPO/>

Conforme esclarecemos, a maior parte dos dados apresentados foram retirados do Censo de 2000 a 2004. Contudo, verificamos uma outra possibilidade de recolha de informações no Diretório dos Grupos de Pesquisa Certificados no Brasil, do CNPq. Nesta base operacional de dados, novas informações foram coligidas, ressalvando-se que está em fase de teste e seus dados foram atualizados recentemente. Este mecanismo de busca permite pesquisar os GPs as LPs a eles ligadas, aqui organizadas em conjunto. Sendo assim, da Plataforma Lattes/Grupo de Pesquisa/Base Corrente retiramos os dados que seguem, de acordo com a ordem inicial da exposição dos verbetes.

Retomando, então, o verbete Ensino de História, área Educação e História, identificamos dados novos. Na Área Educação, de um total de oitenta e um GPs, doze são sobre Ensino de História dos quais cinco não estavam no Censo ${ }^{26}$. Na História temos vinte GPs, dos quais quinze nos interessam e, destes, nove grupos não haviam sido citados. Ressalte-se que entre os nove três GPs foram formados em 2005.

Algumas considerações a mais podemos fazer com os dados abaixo. Por exemplo, foram registrados seis GPs em instituições particulares, estando os demais em instituições públicas; um grupo (Unesp) não registra líder; a formação da grande maioria dos líderes permanece na área História, incluindo graduação em Pedagogia e Ciências Sociais; um possui Pós-Doutorado e um Livre-Docência, pertencendo à instituições públicas (UFPR e Unesp).

QUADRO 23 - GRUPO DE PESQUISA, ENSINO DE HISTÓRIA, ÁREA EDUCAÇÃO E HISTÓRIA

\begin{tabular}{|l|l|l|l|l|}
\hline Filtro & Educação & Novos & História & Novos \\
\hline Ensino de História & 12 & 5 & 15 & 9 \\
\hline
\end{tabular}

FONTE: DISPONÍVEL EM: <HTTP://DGP.CNPQ.BR/BUSCAOPERACIONAL/>

QUADRO 24 - GRUPOS E LINHAS DE PESQUISA, ENSINO DE HISTÓRIA, ÁREA EDUCAÇÃO E HISTÓRIA

\begin{tabular}{|l|l|l|l|l|l|}
\hline Área & Instituições $_{7}^{2}$ & Grupo & Líder & Formação & Linhas \\
\hline Educação & UFPR & Cultura, & Maria & Gr: História & - Cultura, \\
\hline
\end{tabular}




\begin{tabular}{|c|c|c|c|c|c|}
\hline & & $\begin{array}{l}\text { saberes, } \\
\text { práticas } \\
\text { escolares e } \\
\text { educação } \\
\text { histórica (1998) }\end{array}$ & $\begin{array}{l}\text { Auxiliador } \\
\text { a M. S. } \\
\text { Schmidt }\end{array}$ & $\begin{array}{l}\text { Msc: } \\
\text { Educação } \\
\text { Dr: História } \\
\text { Pós-Dr. } \\
\text { Didática da } \\
\text { História } \\
\end{array}$ & $\begin{array}{l}\text { escola e ensino } \\
\text { - Didática e } \\
\text { Educação } \\
\text { Histórica }\end{array}$ \\
\hline Educação & CUML & $\begin{array}{l}\text { Currículo, } \\
\text { história e poder } \\
\text { (2001) }\end{array}$ & $\begin{array}{l}\text { Natalina A. } \\
\text { L. Sicca }\end{array}$ & $\begin{array}{l}\text { Gr: } \\
\text { Pedagogia } \\
\text { Msc: } \\
\text { Educação } \\
\text { Dr: Educação }\end{array}$ & $\begin{array}{l}\text { História da } \\
\text { Educação e } \\
\text { Currículo }\end{array}$ \\
\hline Educação & UEPB & $\begin{array}{l}\text { Ensino, } \\
\text { História e } \\
\text { Formação } \\
\text { Docente }\end{array}$ & $\begin{array}{l}\text { Maria de } \\
\text { Lourdes B. } \\
\text { de Oliveira }\end{array}$ & $\begin{array}{l}\text { Gr: } \\
\text { Pedagogia } \\
\text { Msc: } \\
\text { Educação } \\
\text { Dr: Educação }\end{array}$ & $\begin{array}{l}\text { História da } \\
\text { Escolarização }\end{array}$ \\
\hline Educação & UNESC & $\begin{array}{l}\text { GEPHAE - } \\
\text { Grupo de } \\
\text { Estudos e } \\
\text { Pesquisa em } \\
\text { História e } \\
\text { Acervos } \\
\text { Educacionais } \\
\text { (2004) }\end{array}$ & $\begin{array}{l}\text { Fábia Liliã } \\
\text { Luciano }\end{array}$ & $\begin{array}{l}\text { Gr: } \\
\text { Pedagogia } \\
\text { Msc: } \\
\text { Educação } \\
\text { Dr: Educação }\end{array}$ & $\begin{array}{l}\text { - História da } \\
\text { Educação } \\
\text { Catarinense } \\
\text { - História da } \\
\text { Educação e } \\
\text { Gênero } \\
\text { - História na } \\
\text { Educação no } \\
\text { Brasil } \\
\text { - Memória da } \\
\text { Escola, do } \\
\text { Ensino e da } \\
\text { Docência } \\
\text { Catarinense }\end{array}$ \\
\hline Educação & UNESP & $\begin{array}{l}\text { História da } \\
\text { Educação no } \\
\text { Brasil (1998) }\end{array}$ & $\begin{array}{l}\text { Carlos R. } \\
\text { S. } \\
\text { Monarcha }\end{array}$ & $\begin{array}{l}\text { Gr: Ciências } \\
\text { Sociais } \\
\text { Msc: } \\
\text { Educação } \\
\text { Sociais } \\
\text { Dr: Educação } \\
\text { Livre- } \\
\text { Docente }\end{array}$ & \\
\hline História & UNESP & $\begin{array}{l}\text { Ensino de } \\
\text { História nas } \\
\text { Séries Iniciais } \\
\text { do Ensino } \\
\text { Fundamental } \\
\text { (2002) }\end{array}$ & $\begin{array}{l}\text { Sem Líder } \\
\text { Registrado }\end{array}$ & & $\begin{array}{l}\text { Ensino de } \\
\text { História }\end{array}$ \\
\hline História & UEL & $\begin{array}{l}\text { Gênero e } \\
\text { História (2002) }\end{array}$ & $\begin{array}{l}\text { Maria de } \\
\text { Fátima da } \\
\text { Cunha } \\
\text { Edméia A. } \\
\text { Ribeiros }\end{array}$ & $\begin{array}{l}\text { Gr: História } \\
\text { Msc: História } \\
\text { Dr: História } \\
\text { Gr: História } \\
\text { Msc: História } \\
\text { Dr: História }\end{array}$ & $\begin{array}{l}\text { História e } \\
\text { Ensino }\end{array}$ \\
\hline História & UNIVILLE & $\begin{array}{l}\text { Historia e } \\
\text { Educação } \\
\text { (2003) }\end{array}$ & $\begin{array}{l}\text { Iara A. } \\
\text { Costa }\end{array}$ & $\begin{array}{l}\text { Gr: História } \\
\text { Msc: } \\
\text { Educação }\end{array}$ & História Social \\
\hline
\end{tabular}




\begin{tabular}{|c|c|c|c|c|c|}
\hline História & UFCG & $\begin{array}{l}\text { Historiografia e } \\
\text { Ensino de } \\
\text { História (2005) }\end{array}$ & $\begin{array}{l}\text { Marinalva } \\
\text { V. Lima }\end{array}$ & $\begin{array}{l}\text { Gr: história } \\
\text { Msc: História } \\
\text { Dr: História } \\
\text { Social }\end{array}$ & $\begin{array}{l}\text { - História, } \\
\text { memória e } \\
\text { educação } \\
\text { patrimonial } \\
- \\
\text { Historiografia e } \\
\text { pesquisa em } \\
\text { História } \\
\text { - Metodologia } \\
\text { e pesquisa em } \\
\text { História }\end{array}$ \\
\hline História & UFCG & $\begin{array}{l}\text { História, } \\
\text { Ensino e } \\
\text { Estudos } \\
\text { Culturais } \\
\text { (2005) }\end{array}$ & $\begin{array}{l}\text { Roberval S. } \\
\text { Santiago }\end{array}$ & $\begin{array}{l}\text { Gr: História } \\
\text { Msc: História } \\
\text { Dr: História }\end{array}$ & $\begin{array}{l}\text { História, } \\
\text { Ensino e } \\
\text { Estudos } \\
\text { Culturais }\end{array}$ \\
\hline História & UNIVALI & $\begin{array}{l}\text { História, } \\
\text { Memória e } \\
\text { Ensino (2004) }\end{array}$ & $\begin{array}{l}\text { José Bento } \\
\text { R. Silva }\end{array}$ & $\begin{array}{l}\text { Gr: História } \\
\text { Msc: História } \\
\text { Dr: História }\end{array}$ & $\begin{array}{l}\text { - História, } \\
\text { Memória e } \\
\text { Cidades: } \\
\text { História da } \\
\text { Cidade } \\
\text { - } \\
\text { Especialização, } \\
\text { urbanização e } \\
\text { tensões urbanas } \\
\text { - Memória e } \\
\text { esquecimentos } \\
\text { nas cidades } \\
\text { - História das } \\
\text { instituições } \\
\text { escolares dos } \\
\text { fazeres } \\
\text { pedagógicos } \\
\text { - História do } \\
\text { Ensino de } \\
\text { História }\end{array}$ \\
\hline História & PUC/SP & $\begin{array}{l}\text { Núcleo de } \\
\text { Estudos } \\
\text { Culturais: } \\
\text { Histórias, } \\
\text { Memórias e } \\
\text { Perspectivas do } \\
\text { Presente (1996) }\end{array}$ & $\begin{array}{l}\text { Yara Maria } \\
\text { Aun } \\
\text { Khoury }\end{array}$ & $\begin{array}{l}\text { Gr: História } \\
\text { Msc: História } \\
\text { Dr: } \\
\text { Sociologia }\end{array}$ & $\begin{array}{l}\text { - Ensino de } \\
\text { História } \\
\text { - Linguagens, } \\
\text { História e } \\
\text { Memória }\end{array}$ \\
\hline História & UNISA & $\begin{array}{l}\text { História Socail } \\
\text { (2004) }\end{array}$ & $\begin{array}{l}\text { Luiz } \\
\text { Antonio } \\
\text { Dias }\end{array}$ & $\begin{array}{l}\text { Msc: História } \\
\text { Dr: História }\end{array}$ & \\
\hline História & UVA & $\begin{array}{l}\text { História Social } \\
\text { e Memória } \\
\text { (2005) }\end{array}$ & $\begin{array}{l}\text { Chrislene } \\
\text { C. Santos }\end{array}$ & $\begin{array}{l}\text { Msc: História } \\
\text { Dr: História }\end{array}$ & $\begin{array}{l}\text { - História, } \\
\text { Memória e } \\
\text { Gênero } \\
\text { - Linguagens, } \\
\text { iconografia e } \\
\text { Ensino de } \\
\text { história }\end{array}$ \\
\hline
\end{tabular}

FONTE: DISPONÍVEL EM: <HTTP://DGP.CNPQ.BR/BUSCAOPERACIONAL/> 
O levantamento efetuado com os filtros Didática de História e Educação Histórica nas áreas de Educação e História indicou informações já apontadas pelo Censo e duas novas as quais destacamos a seguir.

QUADRO 25 - GRUPOS DE PESQUISA, DIDÁTICA DA HISTÓRIA E EDUCAÇÃO HISTÓRICA, ÁREA EDUCAÇÃO E HISTÓRIA

\begin{tabular}{|l|l|l|l|l|}
\hline Filtro & Educação & Novos & História & Novos \\
\hline Didática da História & 2 & 1 & 1 & - \\
\hline Educação Histórica & 4 & 1 & 1 & - \\
\hline
\end{tabular}

FONTE: DISPONÍVEL EM: <HTTP://DGP.CNPQ.BR/BUSCAOPERACIONAL/>

Em termos de GPs, em Didática da História, na área Educação, isto é, relativos a outras disciplinas, temos 14, mas somente dois são da área pesquisada (UFPR e UESB). O primeiro (UFPR) foi registrado com o mesmo filtro pelo Censo. O segundo GP, no Estado da Bahia (UESB), traz informações novas, conforme mostrará o quadro. Na área História, o GP referido (UFBA) não é novo, portanto não é destacado no quadro que segue.

QUADRO 26 - GRUPOS DE PESQUISA, DIDÁTICA DA HISTÓRIA, ÁREAS EDUCAÇÃO E HISTÓRIA

\begin{tabular}{|c|c|c|c|c|c|}
\hline Área & $\begin{array}{c}\text { Instituição } \\
\mathbf{8}\end{array}$ & Grupo & Líder & Formação & Linhas \\
\hline Educação & UESB & $\begin{array}{c}\text { Museu } \\
\text { Pedagógico: } \\
\text { a educação } \\
\text { escolar }\end{array}$ & $\begin{array}{c}\text { Lívia Diana } \\
\text { Rocha } \\
\text { Magalhães }\end{array}$ & $\begin{array}{c}\text { Gr: Pedagogia } \\
\text { Msc: } \\
\text { Educação } \\
\text { Dr: Educação }\end{array}$ & $\begin{array}{c}\text { Educação, } \\
\text { cultura e } \\
\text { reformas } \\
\text { educacionais: } \\
\text { memória, } \\
\end{array}$ \\
& $(2000)$ & & & $\begin{array}{c}\text { história e } \\
\text { cultura } \\
\text { escolar. }\end{array}$ \\
\hline
\end{tabular}

FONTE: DISPONÍVEL EM: <HTTP://DGP.CNPQ.BR/BUSCAOPERACIONAL/>

O verbete Educação Histórica, nas áreas Educação e História, evidencia 12 grupos, quatro da área pesquisada (UFPR, UFMG, UFBA e UFJF), três deles já referidos na pesquisa com o filtro Ensino de História e/ou Didática da História. Neste sentido, a UFJF constitui grupo novo na área Educação e sua data de formação foi 2005. É interessante ressaltar que a líder do GP apareceu em outro GP, pesquisado pelo filtro Ensino de História, área Educação, entre 2000 e 2004. Já na área História, dos dois grupos registrados, um pertence ao campo da pesquisa (UFBA), mas havia sido referido em Didática da História.

QUADRO 27 - GRUPOS E LINHAS DE PESQUISA, EDUCAÇÃO HISTÓRICA, ÁREAS EDUCAÇÃO E HISTÓRIA 


\begin{tabular}{|l|l|l|l|l|l|}
\hline Área & Instituição & Grupo & Líder & Formaçao & Linhas \\
\hline Educação & UFJF & História Ensinada, & Li: Sonia & Gr: História & - Memória e \\
& & Memória e Saberes & Regina & Msc: História & espaços sociais \\
& & escolares (2005) & Miranda & Dr: Educação & de educação \\
& & & & & histórica \\
& & & & & - Práticas \\
& & & & & pedagógicas e \\
& & & & & ensino de \\
& & & & & História \\
\hline
\end{tabular}

FONTE: DISPONÍVEL EM: <HTTP://DGP.CNPQ.BR/BUSCAOPERACIONAL/>

\section{Considerações finais}

Conclusões preliminares indicam que houve um crescimento dos grupos de investigação sobre as questões relacionadas ao ensino de História, particularmente nos programas de pós-graduação.

Indicam também que parece estar em curso um processo de definição da identidade destes grupos, o que pode ser evidenciado pelos indicadores que permitiram a sua sistematização, tais como Didática da História, Ensino de História e Educação Histórica. Esta definição parece estar relacionada, também, aos espaços onde os grupos estão localizados, na História e na Educação.

Um elemento a destacar é o aparecimento de um campo de investigação denominado Educação Histórica, revelando um início de investigações desta área no Brasil, desvinculada da História da Educação.

\section{REFERÊNCIAS}

BRASIL. Conselho Nacional de Desenvolvimento Científico e Tecnológico - CNPq. Diretório de Grupos de Pesquisa. Disponível em: <http://dgp.cnpq.br/buscagrupo/> Acesso em: 5 dez. 2005.

BRASIL. Conselho Nacional de Desenvolvimento Científico e Tecnológico - CNPq. Busca Textual. Disponível em: <http://buscatextual.cnpq.br/buscatextual/buscapesq.jsp> Acesso em: 5 dez. 2005.

BRASIL. Conselho Nacional de Desenvolvimento Científico e Tecnológico - CNPq. Diretório de Grupos de Pesquisa. Censo de 2004. Disponível em: <http://dgp.cnpq.br/ censo2004/sumula_estat/index_grupo.htm> Acesso em: 5 dez. 2005.

BRASIL. Conselho Nacional de Desenvolvimento Científico e Tecnológico - CNPq. Diretório de Grupos de Pesquisa. Busca operacional. Disponível em: <http://dgp.cnpq.br/ buscaoperacional/> Acesso em: 15 jan. 2006.

Texto recebido em 16 fev. 2005

Texto aprovado em 17 nov. 2005 
* Doutora em História da Educação, Professora na Universidade Federal de Santa Catarina, Brasil. E.mail: olinda@ced.ufsc.br

*** Bolsista PIBIC, Curso de Pedagogia - Universidade Federal de Santa Catarina. E.mail: jtriches@yahoo.com.br

${ }^{1} \mathrm{O}$ trabalho foi realizado com base na Busca Textual que "permite recuperar dinamicamente informações individualizadas sobre qualquer dado presente nas bases do Diretório, relativo aos censos de 2004, 2002 e 2000. Inclui três possibilidades de recuperação de informações, em níveis crescentes de complexidade busca simples, orientada e avançada. Organiza-se a partir de três decisões iniciais tomadas pelo usuário: (i) qual informação deverá ser recuperada (busca simples); (ii) onde esta informação deverá ser procurada (orientada e avançada); e (iii) segundo quais critérios deverá ser buscada (orientada e avançada). A busca avançada requer um conhecimento elementar de aplicações de lógica booleana.” CNPq. Disponível em: <http://dgp.cnpq.br/censo2004/inf_gerais/index_que_eh.htm> Acesso em: 05 dez. 2005.

${ }^{2}$ UFJF - Universidade Federal de Juiz de Fora/MG; Fidene - Fundação de Integração, Desenvolvimento e Educação do Noroeste do Estado do Rio Grande do Sul; UFMG - Universidade Federal de Minas Gerais; Unicamp - Universidade Estadual de Campinas/SP; USP - Universidade Estadual de São Paulo; UFES Universidade Federal do Esprito Santo; UFF - Universidade Federal Fluminense; UFF - Universidade Federal Fluminense; UERJ - Universidade Estadual do Rio de Janeiro; UFSC - Universidade Federal de Santa Catarina; UFPB - Universidade Federal da Paraíba; UFU - Universidade Federal de Uberlândia/MG.

${ }^{3}$ GP Ensino de História.

${ }^{4}$ GP Ensino de História: Cognição e Cultura.

${ }^{5}$ GP Ensino de História.

${ }^{6}$ GP História e Educação: Saberes e Práticas.

${ }^{7}$ GP Ensino de História e de Ciências Sociais.

${ }^{8}$ GP Práticas de Ensino e Formação de Professores.

${ }^{9}$ GP Núcleo Inter-disciplinar de Pesquisa no Ensino de História.

${ }^{10}$ GP Educação, História e Sociedade.

${ }^{11}$ GP Formação Docente, Saberes e Práticas de Ensino de História.

${ }^{12}$ É preciso esclarecer que o fato de um grupo s aparecer no ano de 2004 não corresponde sua inexistência anterior. O processo de cadastramento de GPs relativamente recente; de outro lado, podem existir grupos ainda não cadastrados ou cadastrados com outro nome ou com dados não atualizados na base do CNPq.

${ }^{13}$ UECE - Universidade Estadual do Cear; UEL - Universidade Estadual de Londrina; UFPEL Universidade de Pelotas/RS; UNEB - Universidade Estadual da Bahia; UERJ - Universidade do Estado do Rio de Janeiro; FURG - Fundação Universidade do Rio Grande; UFCG - Universidade Federal de Campina Grande/PB; UFMT - Universidade Federal de Mato Grosso; Unifra - Centro Universitário Franciscano de Santa Maria/RS.

${ }^{14}$ GP História e Ensino de História.

${ }^{15}$ GP Ensino - Aprendizagem de História.

${ }^{16}$ GP GISEH - Grupo de Investigações sobre o Ensino de História.

${ }^{17}$ GP Oficinas de História.

${ }^{18}$ GP Espaço Público, Cotidiano Escolar: Ecologia e História.

${ }^{19}$ GP História, Cultura e Sociedade.

${ }^{20}$ GP HISMEC.

${ }^{21}$ GP Scriptorium - Laboratrio de Estudos Medievais.

${ }^{22}$ GP Cultura e Grupos Sociais.

${ }^{23}$ Fidene - Fundação de Integração, Desenvolvimento e Educação do Noroeste do Estado do Rio Grande do Sul; UFMG - Universidade Federal de Minas Gerais; UFF - Universidade Federal Fluminense;

${ }^{24}$ UFPEL - Universidade Federal de Pelotas/RS; UFF - Universidade Federal Fluminense.

${ }^{25}$ As datas de formação dos GPs variam de 1998 a 2004.

${ }^{26}$ CUML - Centro Universitário Moura Lacerda/SP; UEPB - Universidade Estadual da Paraíba/PB; Unesc - Universidade do Extremo Sul Catarinense/SC; Unesp - Universidade Estadual Paulista/SP; UEL - Universidade Estadual de Londrina/PR; Univille - Universidade da Região de Joinville/SC; UFCG Universidade Federal de Campina Grande/PB; Univille - Universidade do Vale do Itaja/SC; Unisa Universidade de Santo Amaro/SP; UVA - Universidade Estadual Vale do Acara/CE.

2727 UESB - Universidade Estadual do Sudoeste da Bahia/BA

${ }^{28}$ UFJF - Universidade Federal de Juiz de Fora/SP; UFBA - Universidade da Bahia. 